\title{
RESEARCH OF EFFECT OF LOW FREQUENCY MAGNETIC FIELD ON GERMINATION, GROWTH AND FRUITING OF FIELD TOMATOES
}

\author{
Jaroslav JEDLIČKA*, Oleg PAULEN, Štefan AILER \\ Slovak University of Agriculture in Nitra, Slovak Republic
}

\begin{abstract}
In the study regarding with tomatoes, the impact of extremely low frequency electromagnetic fields on seed germination of tomato (Solanum lycopersicum L.) after treatment before sowing, as well as the growth following electromagnetic stimulation of young plants at a time before planting in the field, and fruittraits was investigated. In the experiments conducted in two consecutive years (2012 and 2013), we followed the time of seed germination of tomato variety "Pavlina", plant growth and the fruitsize. Magnetization of seeds and young plants was carried out in laboratory conditions, and plant growth and fruits were followed in field conditions where plants were grown on experimental plots $\left(25.0 \mathrm{~m}^{2}\right)$. The plants were grown in accordance with the standards of agricultural practice for tomato. At the generative phase, fruits were collected at regular intervals, and their number and weight were evaluated. Low frequency electromagnetic fields acting at the three inductance levels (20,40 and $60 \mathrm{mT})$ and exposure of 20 minutes a day with frequency of $50 \mathrm{~Hz}$, significantly influenced the germination, plant growth and fruitsize of the studied tomato variety.
\end{abstract}

Keywords: tomato, low electromagnetic field, germination, growth

Tomato crop is demanding, requiring thorough approach to the growing technology. It requires a warm location, ample moisture, especially at the time of fruit ripening. Irrigation water should not be applied onto leaves and fruits in order to prevent fruit cracking and spreading of fungal diseases due to wet leaves.

In the experiment, we investigated the effect of lowfrequency static magnetic fields on germination, growth and fruits of tomato variety 'Pavlina' which is medium early variety, with determinant growth and robust stature, suitable for the cultivation of maize and beet production regions of Slovakia. The fruits are firm, sweet, suitable for direct consumption and have a shelf life of 2-3 weeks.

Electromagnetic stimulation of seed as well as stimulation of plant growth are among environmentally sound pre-sowing treatment techniques, and should be assigned to the non-invasive, environmentally clean and friendly technologies (Aguilar et al., 2009; Nimm and Madhu, 2009), suitable for organic farming (Aladjadjiyan, 2010; Bilal et al., 2012) and for weakening of seed dormancy (Carbonell et al., 2004; Ratushnyak et al., 2008; Pittman, 1977; Alikamanoglu and Sen, 2011).

The magnetic field effects living systems in interaction of its size and nature of exposure to biological material. It influences cells, tissues, and the other organs and organ systems in different ways (Belyavskaya, 2004; Ottová and Leitmanová, 1993; Toroptsev and Taranov, 1982). Studies in cells and organisms of plants confirmed that magnetic fields affected the metabolism of cells (Belyavskaya et al., 1992;
Dardeniz et al., 2006). Sleper et al. (2008) in their studies found that biological stimulation as influenced by abiotic factors played an important role in optimizing crops in terms of germination. Positive impact on germination and growth of plants mentioned in his study Aladjadjiyan (2002) and reported stimulative effect of the energy of magnetic field on the development and morphological characteristics of the plants. According to the same author (Aladjadjiyan, 2010), electromagnetic fields have a positive effect on the paramagnetic properties of some atoms in plant cells and pigments in them. In studies of Rajendra et al. (2005), the authors proved that magnetic fields stimulated germination and growth of selected varieties of beans and peas, noting improvement in germination parameters and higher yields. Masafumi, Takuya and Wataru (1998) in their study reached better formation of roots of seedlings of maize, compared with the control group as a result of magnetic fields influence. Fischer et al. (2004) in their experiment exposed sunflower seedlings to magnetic field, and achieved small yet significant increase in the total green plant weight compared to the control plants. The studies of authors (Kavi, 1977; Lebedev et al., 1977) state that in electromagnetically treated tomato seeds, there was confirmed biostimulation effect of those fields in the early stages of germination and growth. De Souza et al. (2006) report that electromagnetic tomato seed treatment resulted in a significant increase in leaf area, leaf dry weight, average weight of the fruits as well as an increase in harvest of tomatoes per unit area. Martínez 
et al. (2009) in their study indicated shortening of seed germination period of magnetically treated tomato seeds.

\section{Objective}

The aim of the study was to determine the effects of low frequency electromagnetic fields on germination, growth and fruits of tomato variety 'Pavlina'.

\section{Material and methods}

A part of the experiment was conducted in laboratory conditions - magnetization of tomato seeds of 'Pavlina' variety, and the magnetization of the young plants until the date of planting in open field. Seeds and young plants were exposed to electromagnetic field (EMF) at the level of induction of $20 \mathrm{mT}$ (variant 1), $40 \mathrm{mT}$ (option 2), or $60 \mathrm{mT}$ (variant 3), with the same frequency $(50 \mathrm{~Hz})$ and the exposure time of 20 minutes a day. Magnetization of plants was performed every day within 48 days. Seeds and young plants in the control variant (variant 4) were not exposed to EMF.

The electromagnetic induction coil used in the experiment was made based on own project, taking into account the requirements of the experiment. An induction coil with an internal diameter $2 \mathrm{R}=55 \mathrm{~cm}$ (Figure 1) created a magnetic field defined according to Horak and Krupka (1976) relationship for the solenoid.

\section{Description of electromagnetic inductor.}

Electromagnetic inductor (coil) used in the experiment is composed of:

- Supply network driver.

- Voltage transducer.

- Magnetic induction meter.

- Leading wires to the induction coil.

- Cylindrical induction coil.

The tomato seeds were sown on March 10 into trays with universal substrate, and were regularly irrigated afterwards. After germination and forming of first pair of true leaves, young plants were transplanted and grown under cover until May 15. Growing space with young plants after germination was ventilated to maintain a temperature of $15{ }^{\circ} \mathrm{C}$, after transplanting day, it was increased to approximately $25^{\circ} \mathrm{C}$, and $15^{\circ} \mathrm{C}$ during night hours.

Tomato plants were planted in field conditions for experimental fields on May 15, into light soil, rich in humus, at spacing $0.5 \times 0.5 \mathrm{~m}$. Surface irrigation was used according to need (soil moisture level).

In the first phase of the experiment, the period of germination and growth of young plants (above-ground and underground part) were monitored, after planting in open field, production of fruit was assessed (quantity and weight of ripe fruit). The results of the experiment were evaluated statistically by analysis of variance.

\section{Results and discussion}

The times required for germination of seeds are given in Table 1.

As to the time needed for seed germination, the shortest period was recorded in the second experimental variant (40 $\mathrm{mT})$ - shorter by 3 days (50\%) compared to untreated seed. The longest period of germination was found in the control variant $(0 \mathrm{mT})-6$ days $(P<0.001)$.

Growth of young plants under cover is shown in Table 2. Electromagnetic field had a significant impact on the growth characteristics of both aboveground part and roots of the experimental plants. The strongest growth was recorded in the second experimental variant in which aboveground part reached $0.45 \mathrm{~m}$ in average (55.2\% compared to the control variant), and root length reached $0.36 \mathrm{~m}$ (71.4\%). The weakest growth was recorded in the control variant e.g. $0.29 \mathrm{~m}$ (aboveground part) and $0.21 \mathrm{~m}$ (roots). These differences were significant at $P<0.001$.

Average weight of tomato fruits harvested at the time of maturity reached in the experimental variants is shown in Table 3.

The highest mean weight of ripe fruit was observed in the second experimental variant (159 g), which was by $11.2 \%$ higher compared with the lowest mean fruit weight achieved in the control variant $(143 \mathrm{~g})$, and the difference was significant $(P<0.01)$. In all experimental variants, the mean fruit weight was higher than that recorded in control variant.

Treatment of seeds of tomato variety 'Pavlina', as well as the young plants with electromagnetic fields at different induction levels $(20,40$ and $60 \mathrm{mT})$, single exposure of 20 minutes a day by planting in the experimental open field significantly affected seed germination and subsequent growth of young plants, as well as the size of the fruits. The magnetically treated tomato seeds showed shortened germination period, and also faster growth of seedlings was recorded, greater length above ground (stem) and underground (root) systems, and earlier fruit setting up to 14 days compared to tomatoes in the control variant. Plants exposed to EMF produced larger fruit - mean weight of tomatoes in the second experimental variant was higher by 17 grams than that in the control variant $(0 \mathrm{mT})$. Fruits of the tomatoes ripened evenly, which may have major economic importance.

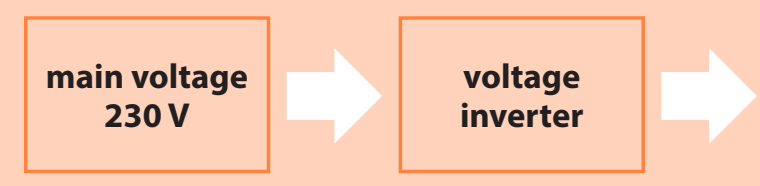

inductor

Figure 1 Block diagram of the device 
Table 1 Period of seed germination

\begin{tabular}{|c|c|c|c|c|}
\hline Variant & EV1 & EV2 & EV3 & CV \\
\hline Induction level (B) & $20 \mathrm{mT}$ & $40 \mathrm{mT}$ & $60 \mathrm{mT}$ & $0 \mathrm{mT}$ \\
\hline $\begin{array}{l}\text { Germination period } \\
\text { (days) }\end{array}$ & $\begin{array}{c}4.0 \\
33.3 \% \\
*\end{array}$ & $\begin{array}{c}3.0 \\
50 \% \\
* * *\end{array}$ & $\begin{array}{c}3.5 \\
41.6 \% \\
* *\end{array}$ & $\begin{array}{c}6 \\
* * * ; * * ; *\end{array}$ \\
\hline
\end{tabular}

$\mathrm{EV} 1$ - first experimental variant, EV2 - second experimental variant, EV3 - the third experimental variant, $\mathrm{CV}$ - control variant, $* * * P<0.001,{ }^{* *} P<0.1, * P<0.5$

Table 2 Growth of plants in experimental variants prior to planting to field conditions

\begin{tabular}{|l||c|c|c|c|}
\hline Variant & $\mathrm{EV} 1$ & $\mathrm{EV} 2$ & $\mathrm{EV} 3$ & $\mathrm{CV}$ \\
\hline Induction level (B) & $20 \mathrm{mT}$ & $40 \mathrm{mT}$ & $60 \mathrm{mT}$ & $0 \mathrm{mT}$ \\
\hline \hline & 0.32 & 0.45 & 0.38 & 0.29 \\
\hline Aboveground part (m) & $10.3 \%$ & $55.2 \%$ & $31.0 \%$ & $* * * * * *$ \\
& & $* * *$ & 0.29 & 0.21 \\
\hline $\begin{array}{l}\text { Underground part } \\
\text { root (m) }\end{array}$ & 0.22 & 0.36 & $38.1 \%$ & $* * * * * *$ \\
\end{tabular}

EV1 - first experimental variant, EV2 - second experimental variant, EV3 - third experimental variant, CV - control variant, *** $P<0.001, * * P<0$

Table 3 Average weight of tomato fruits harvested at the time of maturity reached in the experimental variants

\begin{tabular}{|l||c|c|c|c|}
\hline Variant & EV1 & EV2 & EV3 & CV \\
\hline \hline Induction level (B) & $20 \mathrm{mT}$ & $40 \mathrm{mT}$ & $60 \mathrm{mT}$ & $0 \mathrm{mT}$ \\
\hline \multirow{3}{*}{ Mean fruit weight (g) } & 147 & 159 & 151 & 143 \\
& $2.8 \%$ & $11.2 \%$ & $5.6 \%$ & $* *$ \\
\hline
\end{tabular}

EV1 - first experimental variant, EV2 - second experimental variant, EV3 -third experimental variant, CV - control variant, ${ }^{* *} P<0.1$

In all experimental variants (EV1, EV2 and EV3), we observed a positive effect of magnetic fields on all monitored parameters of the experiment, compared to plants and fruits in the control variant.

References on the biological effects of magnetic fields have shown that the magnetic field can cause or change number of phenomena, such as the increase in the expression of calcium channels (Belyavskaya, 2004).

Studies carried out by the authors Aksyonov et al. (2001) confirmed that the 15 minute treatment of seeds of wheat by the magnetic field of induction of $30 \mathrm{mT}$ caused amplification of root growth by nearly $25 \%$, while the length of the stems of the plants was higher by $40 \%$ compared to the control plants. Alexander et Doijode (1995) reports that the use of the magnetic field within the seed treatment before germination improved root growth and viability of rice and onions. Similar results reported Murphy (1994) and Phirke et al. (1996).

In experiments with magnetically treated lettuce seeds, Garcia et al. (2001) have found their earlier germination compared with untreated seeds, which could be due to increasing the amount of water absorbed. Even Hoff (1981) in his experimental results indicated the impact of magnetic fields to increase of the intensity of photosynthesis and water penetration during the growth of the treated plants. Earlier germination in magnetically treated seeds of tomatoes in their study was also mentioned by Martinez et al. (2009). Vashisth and Nagarajan (2010) attributed increased activity of hydrolytic enzymes to a shorter period of germination of magnetically treated sunflower seed.
De Souza et al. (2006) and Socorro et al. (1999), De Koning (1993), his experiments with magnetically treated seeds of tomatoes confirmed higher mean fruit weight of tomatoes, as well as their overall higher yields, which is consistent with our findings.

\section{Conclusion}

In the experiment, we investigated the effect of lowfrequency electromagnetic field on seed germination, growth of young plants and fruit size of tomato variety 'Pavlina. We found that:

1. Low-frequency electromagnetic fields have had a stimulatory effect on germination, growth characteristics and size of tomato fruit.

2. The effects of magnetic fields on growth apices of tomatoes varied depending on the level of induction.

3. Treatment of tomato seeds and young plants with electromagnetic field at the time before planting in field conditions also influences the production of fruit.

4. Exposure of seeds and young plants to magnetic field in all the variations leads to achieving better quantitative results compared to that obtained with the control treatment; we also observed better fruit quality parameters.

5. Faster germination and growth of young plants during their growing in protected areas may have a major economic impact, whereas shortening of growing period saves energy costs and subsequent earlier ripening can bring direct benefits due to higher prices of produce. 


\section{References}

AGUILAR, C. H. et al. 2009. Alternative magnetic field irradiation effects on three genotype Maize seed field performance. In Acta Agrophysica, vol. 14, 2009, no. 1, pp. 7-17.

AKSYONOV, S. I. et al. 2007. On the mechanisms of stimulation and inhibition of wheat seed germination by low-frequency magnetic field. In Biophysics, vol. 52, 2007, no. 2, pp. 233-236.

AKSYONOV, S. I. et al. 2001. Effects Of ELF-EMF Treatment On Wheat Seeds At Different Stages Of Germination And Possible Mechanisms Of Their Origin. In Electro Magnetobiol, vol. 20, 2001, no. 2, pp. 231-253.

ALADJADJIYAN, A. 2010. Influence of stationary magnetic field on lentil seeds. In International Agrophysics, vol. 24, 2010, pp. 321-324. ALADJADJIYAN, A. 2002. Study of the Influence of Magnetic Field on Some Biological Characteristics of Zea mais. In Journal of Central Europ. Agric., vol. 3, 2002, no. 2, pp. 89-94.

ALEXANDER, M. P. - Doijode, S. D. 1995. Electromagnetic field, a novel tool to increase germination and seedling vigour of conserved onion (Allium cepa L.) and rice (Oryza sativa L.) seeds with low viability. In Plant Genetic Res. Newsletter, vol. 104, 1995, pp. 1-5.

ALIKAMANOGLU, S. - Sen, A. 2011. Stimulation of growth and some biochemical parameters by magnetic field in wheat (Triticum aestivum L.) tissue cultures. In African Journal of Biotechnology, vol. 10, 2011, no. 53, pp. 10957-10963.

BELYAVSKAYA, N. A. 2004. Biological effects due to weak magnetic field on plants. In Adv. Space Res., vol. 34, 2004, pp. 1566.

BELYAVSKAYA, N. A. et al. 1992. Structural-functional organization of the meristem cells of pea, lentil and flax roots in conditions of screening the geomagnetic field. In Biophysics, vol. 37, 1992, pp. 657-666.

BILALIS, D. J. et al. 2012. Investigation of pulsed electromagnetic field as a novel organic pre-sowing method on germination and initial growth stages of cotton. In Electromagnetic Biology and Medicine, Posted online on January, vol. 23, 2012.

CARBONELL, M. V. et al. 2004. Influence of magnetically treated water on germination of signalgrass seeds. In Seed Science and Technology, vol. 32, 2004, no. 2, pp. 617-619.

DARDENIZ, A. - TAYYAR, S. - YALCIN, S. 2006. Influence of lowfrequency electromagnetic field on the vegetative growth of rape cv. Uslu. In J. Central Euro. Agricult., vol. 7, 389 pp.

DE KONING, A. N. M. 1993. Growth of a tomato crop: Measurements for model validation. In Acta Horticulture, vol. 328, 1993, pp. 141-146.

De Souza, A. 2006. Pre-sowing magnetic treatments of tomato seeds increase the growth and yield of plants. In Bioelectromagnet., vol. 27,2006 , pp. 247-257.

FISCHER, G. et al. 2004. Effect ofweak 162/3 HZ magnetic fields on growth parameters of young sunflower and wheat seedlings. In Bioelectromagnetics, vol. 25, 2004, pp. 638-641.
GARCIA REINA, F. - PASCUAL, L. A. - FUNDORA, I. A. 2001. Influence of a stationary magnetic field on water relations in lettuce seeds. Part II: Experimental Results. In Bioelectromag, vol. 22. 2001, pp. 596-602.

HOFF, A. J. 1981. Magnetic field effects on photosynthetic reactions. In Quarterly Reviews of Biophysics, vol. 14, 1981, no. 4, pp. 599-665. KAVI, P. S. 1977. The effect of magnetic treatment of soybean seed on its moisture absorbing capacity. In Sci. Culture, vol. 43, 1977, pp. 405-406.

MARTINEZ, E. et al. 2009. Germination of tomato seeds (Lycopersicon esculentum L.) under magnetic field. In Int Agrophysics, vol. 23, 2009, pp. 45-49.

MASAFUMI, M. - TAKUYA, A. - WATURU, T. 1998. Primary root growth rate of Zea mays seedlings grown in an alternating magnetic field of different frequencies. In Bioelectrochem. Bioeng., vol. 44, 1998, pp. 271-273.

MURPHY, J. D. 1994. The influence of magnetic fields on seed germination. In Am. J. Botany, 1994, no. 29, pp. 155.

NIMMO, V. - MADHU, G. 2009. Effect of pre-sowing treatment of the permanent magnetic field on germination and growth of chilli (Capsicum annum L.). In Int.Agrophysics, vol. 23, 2009, pp. 195-198. OTTOVÁ-LEITMANOVÁ, A. 1993. Základy biofyziky. Bratislava : Alfa, 1993, $383 \mathrm{~s}$.

PHIRKE, P. S. - KUDBE, A. B. - Umbarkar, S. P. 1996. The influence of magnetic field on plant growth. In Seed Sci. Technol., vol. 24, 1996, pp. 375-392.

PITTMAN, U. J. 1977. Effect of magnetic seed treatment on yields of barley, wheat, and oats in southern Alberta. In Canad. J. Plant Sci., vol. 57, 1977, pp. 37-45.

RATUSHNYAK, E. 2008. Effect of extremely high frequency electromagnetic fields on the microbiologicalcommunity in rhizosphere of plants. In International Agrophysics, vol. 22, 2008, pp. 71-74.

RAJENDRA, P. et al. 2005. Effects of power frequency electromagnetic fields on growth of germinating Vicia faba L., the broad bean. Eletromagn. In Biol. Med, vol. 24, 2005, pp. 39-54.

SOCORRO, A. et al. 1999. Cell model of seed tissue treated with magnetic field. II International Symposium on Applied Nuclear and Related Techniques in Agricultura, In Industry and Environment, La Habana, Cuba, 1999, pp. 26-29.

TOROPTSEV, I. - TARANOV, S. 1982. Morphological characteristics and various theories on the mechanism of biological effect of magnetic fields. In Arkh Patol., 1982, no. 12, 1982, pp. 3-11.

VASHISTH, A. - NAGARAJAN, S. 2010. Effect on germination and early growth characteristics in sunflower (Helianthus annuus) seeds exposed to static magnetic field. In Journal of Plant Physiology, vol. 167, 2010, pp. 149-156. 